\title{
Estados de consciência misticos e Transe capoeirano: uma interpretação da obra de mestre Decanio à luz do pensamento de William James
}

Mystical states of consciousness and capoeira trance: an interpretation of the work of master Decanio in the light of William James' thought

Cicero Cunha Bezerra*

do: $\underline{\text { https://doi.org/10.29327/256659.12.2-17 }}$

Resumo:

As figuras dos mestres Bimba e Pastinha dominam, no geral, os interesses e análises sobre a capoeira, no entanto, dentre os vários mestres que compõem o universo da capoeiragem, há um que, no meu entender, estabelece uma visão extremamente particular da prática da capoeira, a saber: mestre Decanio (1923-2012). Esse artigo tem, portanto, o objetivo de compreender, à luz do pensamento de William James, em especial das suas reflexões presentes em suas conferências sobre os estados místicos de consciência, em que medida é possivel sustentar o caráter místico do transe capoeirano, proposto por Decanio, como uma forma particular de êxtase que ocorre pela interação entre três níveis que constituiriam o psíquico humano: consciente, inconsciente e estados modificados de consciência.

Palavras-chave: Decanio. Capoeira Regional. William James. Transe.

Abstract:

The figures of masters Bimba and Pastinha dominate, in general, the interests and analysis of capoeira.However, among the various masters that make up the universe of capoeira, there is one that, in my understanding, establishes an extremely particular view of capoeira practice, namely: master Decanio (1923-2012). This article, therefore, aims to understand, in the light of William James' thinking, especially his reflections present in his lectures on the mystical states of consciousness, to what extent it is possible to sustain the mystical character of the capoeira trance, proposed by Decanio, as a particular way of ecstasy that occurs through the interaction between three levels that would constitute the human psyche: conscious, unconscious, and modified states of consciousness.

Keywords: Decanio; Regional Capoeira; William James; Trance.

"Doutor em Filosofia pela Universidad de Salamanca (Espanha), Professor Titular do Departamento de Filosofia e dos Programas de Pós-Graduação em Ciências da Religião e Filosofia da Universidade Federal de Sergipe. Pesquisador de Produtividade do CNPq. Email: cicerobezerra@hotmail.com 


\section{Introdução}

O berimbau é muito espiritual. O som do berimbau vem de dentro. E toda a conexão - a energia está no chakra aqui [Naná indica seu tórax e cavidade pulmonar] (NANÁ VASCONCELOS, 2007, p. 50)

A capoeira, como manifestação cultural brasileira, desperta múltiplos interesses em várias áreas do conhecimento. Aspectos sociais, estéticos, educacionais, dentre outros, estimulam uma vasta produção bibliográfica em diversas linguas e formatos (textos, podcast, vídeos, etc.). Angelo Augusto Decanio Filho, mestre Decanio, não é somente um dos mais importantes e exímios capoeiristas "filhos de Bimba". Médico de formação, conhecedor da fisiologia humana, leitor de tradições como a budista, a teosófica, a cristã e a candomblecista, Decanio propõem uma visão do humano a partir da unidade entre corpo, alma e espírito focando no desenvolvimento das capacidades fisico-motoras e, fundamentalmente, espirituais do ser humano.

Uma leitura atenta das suas obras A herança de Mestre Bimba, Filosofia e lógica africanas (1998) e Transe capoeirano, um estudo sobre estrutura do ser humano e modificações de estado de consciência durante a prática da capoeira (2002), ambas analisadas nesse estudo, permite vislumbrar sua complexa interpretação dos elementos técnico-práticos da capoeira associados a elementos religiosos, em particular oriundos do Candomblé e do Budismo.

Tendo iniciado sua prática no Centro de Cultura Física Regional em 1938, sua influência na academia do mestre é pública e reconhecida por todos que com ele conviveram. Segundo o testemunho de Hellio Campos (Mestre Xaréu), Decanio não somente era "um cobra" na arte da capoeiragem, possuindo todas as qualidades de um bom capoeirista, mas, também, como cirurgião, com destacada atuação no campo da medicina como conferencista em eventos nacionais e internacionais (CAMPOS, 2009, p. 280). Em sua obra "A herança de mestre Bimba: Filosofia e lógica africanas" é o próprio Decanio que revela sua participação direta em aspectos internos da academia que vão desde a criação do símbolo da Capoeira Regional até consultas pessoais feitas pelo o seu fundador. Basta dizer que Decanio foi, de todos os alunos, o único a receber, das mãos de mestre Bimba, o grau máximo: o lenço branco.

A grande característica dos escritos de Decanio está no fato dele não se limitar a comentar os aspectos históricos, técnicos ou culturais da sua arte. Ele 
vai mais longe. O que de fato lhe interessa é definir uma visão da capoeira na qual o físico, o mental e o espiritual convergem em uma unidade que tem como pilar uma experiência extática de comunhão que se alinha, perfeitamente, ao que o filósofo William James definiu como estados místicos de consciência (mystical states of consciousness).

Eugene Taylor observa que a compreensão jamesiana de sistemas de crenças conflitantes, à luz da filosofia pragmática, assim como suas reflexões pioneiras sobre as relações entre o cérebro e a mente, com consequências para a ideia de consciência, tiveram impacto profundo e o tornaram-se marco decisivo nos estudos sobre psicologia da religião. Basta dizer que nenhuma obra é mais influente nesse campo do que Varieties of Religious Experience (TAYLOR, 1996, p. 82). Para este trabalho, me interessa somente destacar, da obra de James, as conexões entre estados místicos da consciência e o transe como expressão da unidade na qual categorias como "sujeito" e "objeto", "contemplante" e "contemplado", "humano" e "divino" se desfazem na experiência mística.

Para tanto, visando uma melhor compreensão do tema aqui proposto, divido esse artigo em três partes: a) na primeira, exponho a ideia jamesiana de estados místicos de consciência em seus aspectos centrais presentes em suas conferências XVI e XVII intituladas de Mysticism e publicadas, por primeira vez, em 1902 em sua obra Varieties of Religious Experience; b) em um segundo momento, apresento a noção de "transe capoeirano", como é desenvolvida por mestre Decanio em sua obra de mesmo nome Transe capoeirano, um estudo sobre estrutura do ser humano e modificações de estado de consciência durante a prática da capoeira (2002) para, em seguida (c) apresentar os resultados obtidos, a partir de ambos autores, que permitem sustentarmos a presença de elementos místicos que fazem da capoeira, em consonância com o que sustenta William James, uma experiência de transe espiritual (transport) que, no caso do pensamento de Decanio, se dá como unidade entre jogador e jogo.

\section{a) W. James os estados místicos de consciência}

Em suas duas Conferências sobre misticismo James estabelece quatro pontos centrais para a compreensão do que ele classifica como um estado mental (state of mind) místico (mystical) são eles:

1) Inefabilidade (Ineffability) - definida a partir da "negatividade", isto é, do reconhecimento do seu caráter indizivel, a inefabilidade aproxima os estados 
místi-cos da consciência à afetividade, ou seja, a um experimentar que escapa a toda expressão e, consequentemente, aos estados intelectuais.

2) Qualidade noética (Noetic quality) - sem contradizer ao aspecto de "afetividade" que caracteriza aos estados místicos, o estatuto de conhecimento e, mais, de um conhecimento verdadeiro é comum ser atribuído pelos que vivenciam experiências místicas. Ainda que o intelecto discursivo cesse diante da inefabilidade, o místico não abre mão do valor noético que se expressa como uma "penetração na verdade profunda e insondável ao intelecto discursivo" (JAMES, 2002, p. 295).

3) Transitoriedade (Transiency) - os estados místicos são sempre descritos como efêmeros. James ainda arrisca a limitá-lo a, no máximo, duas horas. São momentos específicos de iluminação ou êxtase que escapam a qualquer controle.

4) Passividade (Passivity) - ainda que existam práticas espirituais que prescrevam determinados exercícios, rituais, atividades corporais etc., há um elemento de supressão da vontade que define os estados místicos como "irresistível", "incontrolável” e que permanece em seus desdobramentos como uma certa recordação fruto de uma "modificação da vida interior" (JAMES, 2002, p. 296). William James aproxima essas características a certas experiências como a escrita automática e o transe hipnótico, no entanto as distingue dos estados místicos precisamente por estas últimas não manterem, após a interrupção, recordações ou consequências transformadoras para o indivíduo.

Estes quatro aspectos constituem o que James nomeia de "grupo de estados místicos" (mystical group), ou seja, estados de consciência peculiares que justificam um estudo cuidadoso que o mesmo realiza tomando, em um primeiro momento, as experiências que não se relacionam diretamente com aspectos religiosos, mas que eclodem da vida cotidiana comum. Mediante uma predisposição mental é possível, segundo James, que diante de uma música, um poema ou mesmo palavras, antes não percebidas, indivíduos possam experimentar estímulos que despertam o que ele chama de suscetibilidade mística (mystical susceptibility).

Um outro aspecto importante sublinhado por James e que aparecerá na obra de Decanio como uma característica definidora do transe capoeirano se refere a um estado mais profundo que consiste, entre outras coisas, na eliminação das relações espaço-temporais graças a dissolução do "eu consciente" seja por 
uso de anestésicos ou "pela sensação da presença imediata de Deus" (JAMES, 2002, p. 304). James cita, entre outras fontes literárias, um fragmento de Walt Whitman como exemplo de uma experiência mística marcada pela unidade com a natureza: "Rapidamente surgiu e se espalhou ao meu redor a paz e o conhecimento que supera todos os argumentos da terra" (WHITMAN apud JAMES, 2002, p. 307).

Trata-se, assim, da ideia da unidade sujeito/natureza que se expressa, na análise de James, em vários níveis e formas de classificações e que perfaz desde narrativas classificadas como patológicas até tradições religiosas. À parte dos exemplos citados por James o que interessa aqui destacar, são os efeitos morais e físicos que as experiências místicas podem propiciar aos que delas desfrutaram. Diz James: “ Para emitir um juízo espiritual de tais estados, não devemos contentar-nos com a terminologia médica superficial, mas devemos inquirir seus frutos para a vida" (JAMES, 2002, p. 320). Para James, ao contrário de debilidade e inatividade indivíduos como Inácio de Loyola, Teresa D’Ávila, Juan de la Cruz, como também destaca Michel Serres, eram pessoas de grandes preparos físicos:

Desconfio que as análises patológicas do misticismo são sempre ignorantes e maldosas, e isto porque exercem sua força sobre uma fragilidade doentia e sua ação sobre a passividade (...). De corpos atléticos e sem nunca adoecerem, santa Teresa d'Ávila e são Francisco de Assis caminhavam centenas de quilômetros pelos relevos áridos da Espanha e da Itália, espargindo-os com fundamentos laboriosos, porque eram sobejamente poderosos e exímios conhecedores das técnicas do corpo (SERRES, 2004, p. 21).

Na mesma linha afirma James:

Os grandes místicos espanhóis, que levaram o hábito do êxtase tão longe como nenhum outro podia levá-lo, parecem ter mostrado, a maioria deles, um espírito e uma energia indomáveis, se consideramos os transes nos quais se deleitavam (JAMES, 2002, p. 320).

Como se pode observar, para ambos filósofos, como dirá, uma vez mais, Serres: "A santidade sucede à saúde como conhecimento e ação" (SERRES, 2004, p. 21). Estes são os pontos que gostaria de destacar na análise jamesiana dos estados místicos de consciência e suas consequências morais e práticas. Estes são dois aspectos importantes que serão destacados no olhar do mestre Decanio 
em suas reflexões sobre o transe capoeirano. Dito isso, passo para o segundo tópico deste trabalho.

\title{
b) Decanio e as modificações de estado de consciência durante a prática da capoeira
}

Na epigrafe que abre sua obra Transe capoeirano: um estudo sobre a estrutura do ser humano e modificações de estado de consciência durante a prática da capoeira, dedicada à sua companheira Bel, Decanio expressa algumas ideias que me parecem fundamentais antes de adentrar na análise do seu texto:

\author{
Durante toda a minha existência \\ Pregressa, atual e futura \\ Você tem sido, é e continuará eternamente \\ O elo entre o Mundo Manifesto e o Oculto. \\ Como Estrela Guia \\ A me conduzir pelo Labirinto Cósmico On- \\ de habita o SER \\ Imagem sagrada do Criador Temporá- \\ ria e periodicamente Manifestada em \\ cada Encarnação \\ Em busca do retorno à Perfeição! \\ Este é o fruto deste reencontro \\ De nossa colaboração e troca de experiências! \\ Que Deus continue a manter A \\ FORÇA, A LUZ e O AMOR \\ Imanentes à nossa geração! (FILHO, 2002, p. 3)
}

Penso que temos um resumo completo da visão de Decanio do mundo como um ciclo contínuo que expressa um ato criador primeiro. Ato este que pode ser tomado como princípio e fim de um brotar que instaura, entre o manifesto e o oculto, a unidade entre o particular e o universal. Em sendo assim, temos: a) Mundo manifesto e o Oculto; b) Labirinto Cósmico onde habita o SER; c) o Cosmos como imagem do Criador; d) Encarnação como manifestação da imagem sagrada do Criador.

As consequências desta visão se evidenciam logo no primeiro parágrafo da obra quando o mestre afirma:

O capoeirista deixa de perceber a si mesmo como individualidade consciente, fusionando-se ao ambiente em que se desenvolve o jogo de capoeira, passa a agir como parte integrante do quadro ambiental e procede como se conhecesse ou percebesse simultaneamente passado, presente e futuro (tudo que ocorreu, ocorre e o- 
correrá a seguir), ajustando-se natural, insensível e instantaneamente ao processo atual (FILHO, 2002, p. 5).

Passado, presente e futuro congregados no instante "já" de um tempo marcado pelo ritmo-melodia ijexá. Muniz Sodré, em seu livro Pensar Nagô, destaca o elemento "bélico" da dança e ritmos africanos que, posteriormente, assumiram formas litúrgicas: "Numa dinâmica regida pelo axé, como é o caso da liturgia afro, a música é primordialmente vibratória, orientando-se pelas modalidades da execução rítmica, do canto e da dança, em que a percussão é fundamental (SODRÉ, 2017, p. 141).

É precisamente na unidade que o praticante, segundo Decanio, "alcança um estado modificado de consciência" (FILHO, 2002, p. 5). Cumpre observar que mesmo aproximando do transe dos orixás, presente no candomblé, no caso do capoeirista, o transe permanece em um tênue, mas ativo controle da consciência vigil (FILHO, 2002, p. 5). ${ }^{1}$ Isso é fundamental posto que estamos tratando de uma luta, ou seja, de um combate e, enquanto tal, torna-se imprescindivel o alerta permanente como condição para o contra-ataque.

Eugene Taylor, ao pensar a transitoriedade da experiência mística em James, observa que mesmo durando apenas "um breve momento na estrutura temporal do experimentador, a sensação de atemporalidade torna sua influência permanentemente duradoura" (TAYLOR, 1996, p. 88).

Entendo permanência como desdobramento, isto é, ação contínua sobre aquele que vivencia a experiência mística ou, o que seria o mesmo, o estado modificado de consciência para Decanio. Para o médico Decanio, o cérebro "funcionaria como um portal de acesso à mente" (FILHO, 2002, p. 5). ${ }^{2}$ Nesse sentido, as vibrações sonoras atuariam diretamente produzindo modificações de estados de consciência e sentimentos (FILHO, 2002, p. 5). Nisso estaria, segundo o mestre, a origem dos orixás que funcionam como espécie de arquétipos de personalidade ou biótipos que eram definidos, originalmente, pelas suas sensibilidades vibratórias aos ritmos e melodias dos toques de atabaque:

Assim, acredito que os cérebros possam ser classificados consoante os seus potenciais vibratórios em categorias de limites de precisão variáveis, como os demais fatos biológicos, que os antigos africanos denominaram de "orixás", tipos fundamentais de comportamento 1 de consciência alcança (desce ou sobe?) determinado estado sob a influência do campo energético sonoro dos atabaques e melopéia do ogans-alabês, o nível de (FILHO, 2002, p. 7). 
Para chegar a sua concepção de estado modificados de consciência, Decanio parte, sem justificar sua escolha, da concepção de Paulo de Tarso expressa em Tessalonicenses, 5, 23: "Que todo o vosso ser, espírito, alma e corpo, sejam atravessados irrepreensiveis para a Vinda do Nosso Senhor Jesus Cristo!" (apudFilho, 2002, p. 8). Para ele, interessa a tripartição paulina delineada pela doutrina da Ressurreição em Corpo, Alma e Espírito para contrapô-la ao que nomeia de "conhecimentos científicos modernos" que, segundo ele, acrescentaram à trilogia paulina os aspectos psico-sócio-culturais alterando, portanto, para uma arquitetura quadrifacetadas do ser humano (FILHO, 2002, p. 8).

Não tenho interesse em realizar aqui uma exposição linear das incursões psicofísicas constitutivas, para Decanio, da natureza humana. Restrinjo-me, apenas, a abordar as relações entre a música e os estados modificados de consciência. Sabemos que a música promove efeitos no cérebro, não somente no humano. Decanio parte, assim, de um quadro geral de influências para chegar à ideia de êxtase, comum a várias religiões e práticas espiritualistas. No caso da sua análise da capoeira, a chave para o transe se encontra no ritmo (FILHO, 2002, p. 22).

O berimbau desempenha o papel central entre os dois niveis, anteriormente citados, ou seja: o manifesto e o oculto ou invisível. Marca determinante, segundo W. James, da vida religiosa (JAMES, 2002, p. 46). A observação mais radical feita pelo mestre Decanio reside em sua afirmação de que não é necessário conhecer a história e a técnica da capoeira. Entre conteúdo e técnicas há o que ele nomeia de capoeira abstrata (FILHO, 2002, p. 22), uma "fonte etérea" que poderia ser acessada por qualquer um que se deixe envolver pelo ritmo e efeitos mântricos dos cantos durante o jogo. Como testemunho, Decanio cita mestre Itapoan que, em conversa, perguntou a Maré como teria aprendido capoeira e o mesmo teria respondido: "vendo os outros jogarem. Gostei. Entrei na roda e joguei" ( $a$ pud FILHO, 2002, p. 22).

Outro exemplo seria o de "Vovô Capoeira", que aos 84 anos teria jogado de forma espontânea em roda do mestre Canelão em Natal/RN. Esses exemplos, mais do que descaracterizar ou negar a técnica adquirida pelos treinos das sequências dos golpes, revelam uma outra possibilidade de compreensão da roda de capoeira como "espaço metafísico" (FILHO, 2002, p. 22). ${ }^{3}$ 
No relaxamento espontâneo, conjugado com a música, o corpo se adapta, como água, propiciando uma interação entre os participantes que fundam a unidade circundante na qual realiza-se uma comunicação atemporal e "anespacial" que Decanio assimila ao satori (FILHO, 2002, p. 23). Trata-se, assim, de uma afirmação na interação em que cada jogador busca, no jogo das vontades de domínio, sobrepor-se, pela percepção direta e antevisão do comportamento, um ao outro.

O próprio Decanio, em conversa com o mestre de judô Yoshida, revela ter experimentado a sensação de não enxergar ou sentir: "notei que não enxergava ou sentia com os órgãos sensoriais habituais a presença ou os movimentos do oponente, apenas sabia o que ele ia fazer!" (FILHO, 2002, p.24). O risco e o perigo, ao contrário de exigirem temor, produzem, graças ao estado modificado de consciência, prazer e estímulo. Diz ele:

Durante o transe capoeirano, o capoerista modifica o seu estado emocional e passa a encarar como prazerosa uma situação de risco imaginário sob a proteção do ritual e vigilância e responsabilidade do Mestre, de modo a facilitar o aprendizado e registo de soluções adequadas às pretensas situações de perigo (FILHO, 2002, p. 20).

Esse aspecto espontâneo do jogo parece contradizer-se com o domínio das estratégias de reação, esquiva e fuga que são possíveis graças ao papel da memória e que, do ponto de vista das experiências exigiria um domínio das possibilidades que o treino e conhecimento técnicos propiciam. O fato é que Decanio parece mais preocupado em equalizar o pragmático da luta com o aspecto involuntário inconsciente que, tanto pode ser alcançado pelo alto nivel técnico, como, também, desenvolvido pela interação e observação decorrentes da vivência direta na roda. Um outro exemplo citado por Decanio de estado modificado da consciência seria o caso de "Pingo de Ouro", capoeirista paraplégico que, sem apoio de muletas, mas motivado pelo axé que envolve a roda, jogava de uma maneira que, segundo Decanio, não conseguira em estado normal de consciência (FILHO, 2002, p. 35).

O caso mais especial de uma ação direta da prática da capoeira, nesse caso como reabilitação dos circuitos nervosos, é o de Mola, Luciano Santos Bispo, que vitimado pela paralisia infantil, aos 7 anos de idade, recuperou os movimentos ao praticar, aos 9 anos, capoeira sob orientação de mestre Zé Dário. Decanio chega a outorgar o estatuto de "milagre" ao caso de Mola que, ao jogar se equilibrava 
perfeitamente, mas ao sair do jogo, apoiava uma das mãos para auxiliar os movimentos ao andar (FILHO, 2002, p. 36).

Para Decanio existe uma inteligência corporal que permite, de forma espontânea e progressiva, um tipo de aprendizado que longe das teorias mais "enfadonhas" possibilitam com que o aprendiz desenvolva suas habilidades sem a preocupação de alcançar uma finalidade objetiva e imediata. Esse tipo de reflexão, muito comum nos escritos de Decanio, revela a capacidade de construção de interfaces culturais que associam capoeira, yoga, judô, candomblé, cristianismo, entre outras manifestações de forma bastante coerente e produtiva. No caso aqui tratado, não seria equivocado pensar que Decanio faz referência a um tipo de aprendizagem que remonta às práticas mais tradicionais como, por exemplo, o tiro ao alvo praticado pelos mestres budistas e que o filósofo Eugen Herrigel em seu belo livro A arte cavalheiresca do arqueiro zen, expressa da seguinte maneira seu exercício árduo e diário no aprendizado da arte do arco:

Aos poucos e cada vez com maior frequência, à medida que se
passavam os dias, consegui estirar o arco e mantê-lo teso com o
corpo relaxado, sem que pudesse explicar como aquilo estava o-
correndo. A diferença qualitativa entre essas poucas tentativas sa-
tisfatórias e as que com frequência fracassavam fizeram com que
eu começasse a entender o que significava estirar o arco espiritu-
almente. Era este, pois, o quid da questão: não se tratava de ne-
nhum ardil técnico, que eu em vão queria descobrir, mas de uma
respiração nova, que me abria inusitadas possibilidades de libe-
ração (HERRIBGEL, 1975, p. 35 , negritos do autor).

O "quid" da questão, tanto para a arte do arco zen budista, como para a capoeira preconizada por Decanio, está nessa compreensão e intimidade espontânea sem preocupações analíticas, como ele mesmo observa, mas em fluência rítmica com o berimbau:

Em conclusão, a capoeira é para ser aprendida no dia a dia das suas rodas, ao lado e sob a supervisão de bons mestres que podem ser até muito bem titulados e cultos, mas sempre dotados da vivência, da experiência e da sabedoria que só o Tempo e a Prática desenvolvem, gravando na intimidade do sistema nervoso, todos os padrões comportamentais, de modo reflexo e espontâneo em circuitos reverberantes bulbomedulares (DECANIO, 2002, p. 29).

É fundamental destacar que o transe, no aspecto aqui tratado une o que há de mais fisiológico ao espiritual. Desde o olhar periférico que, nas palavras de Decanio mantém o controle do campo visual (visão periférica), até as alterações ou modificações da aura, percebidas inconscientemente pelo capoeirista, temos 
uma complexa visão na qual o médico e perito em anatomia humana explora toda a sua vivência no campo da capoeira elaborando uma visão em que metafísica e corporeidade se misturam propiciando um olhar único sobre a capoeira e sua prática.

Em A herança de mestre Bimba - filosofia e lógica africanas da capoeira (1997), no tópico A metafísica da capoeira ${ }^{4}$, texto que acredito complementar o que venho aqui desenvolvendo, Decanio define a capoeira como dança ritual do Ser com a unidade (FILHO, 1997, p. 143). Uma dança que transcende e faz transcender a distinção subconsciente e consciente por uma terceira possibilidade de atenção, bem próxima do que Kitarô Nishida nomeia de experiência pura ou direta (NISHIDA, 1995, p. 41). ${ }^{5}$ No jogo, marcado pela não distinção entre jogadores, o satori é evocado, por Decanio,como similitude da integração ritualística no qual os movimentos e gestos conduzem a uma transfiguração do próprio ser.

William James se refere ao samâdhi como estado de concentração que inicia-se com um ponto específico, como o exemplo da luz dado por Decanio do olhar focado no opositor, passando pela unidade e culminando, junto com a memória e autoconsciência (self-consciousness), na indiferença (JAMES, 2002, p. 311). Decanio não usa a expressão indiferença, mas acredito que possamos tomá-la como o estágio de "automatismo" que vem associado, pelo mestre, ao aspecto instintivo de reação imediata sem o controle volitivo (FILHO, 2002, p. 5). Diz Decanio:

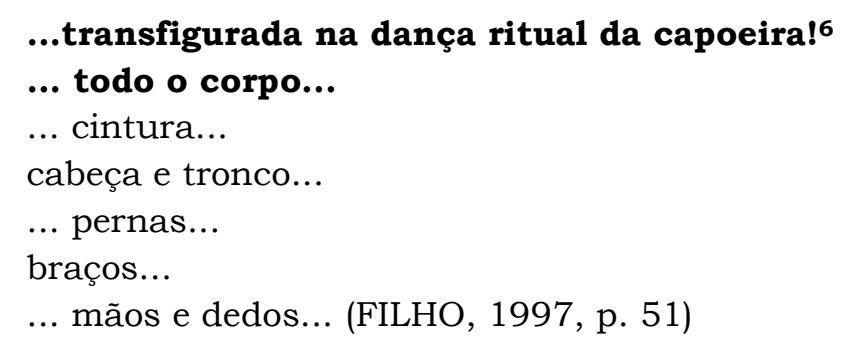

Corpo transfigurado na energia do berimbau ${ }^{7}$ em um espaço infinito em que jogadores e participantes, indistintamente, compõem uma mesma roda, sem dentro nem fora, sem fora nem dentro:

\footnotetext{
... o canto em coro...

... as palmas em sintonia..

... o ritmo/melodia do berimbau...

... num passe de magia ultrapassam os limites da matéria...
} 
... alcançando pela vibração harmônica...

... o êxtase supremo..

... a consciência global...

... o transe coletivo... (FILHO, 1997, p. 147)

Essa passagem se alinha a uma outra que diz:

... alcançamos à Perfeição do Ser...

... a integração psicossomática...

... Mente e Corpo...

... unidos pela magia melódica da capoeira...

... vivenciando o mesmo momento...

... o "Eterno Agora"...

... a concentração mental...

... na perfeição e ritmo dos movimentos...

... remove da consciência...

... os fatores de tensão ou estresse! (FILHO, 1997, p. 202)

Decanio insiste, em várias passagens das duas obras aqui citadas, no candomblé como raiz mística da capoeira. A música como elemento condutor para o estado de "orixás" ou de santo, como ele define, é a porta de entrada para o transe, na melodia do berimbau, ao modo africano do iorubás (Filho, 2002, p.22). O esquema elaborado por ele pode nos ajudar a compreender melhor o tema aqui tratado:

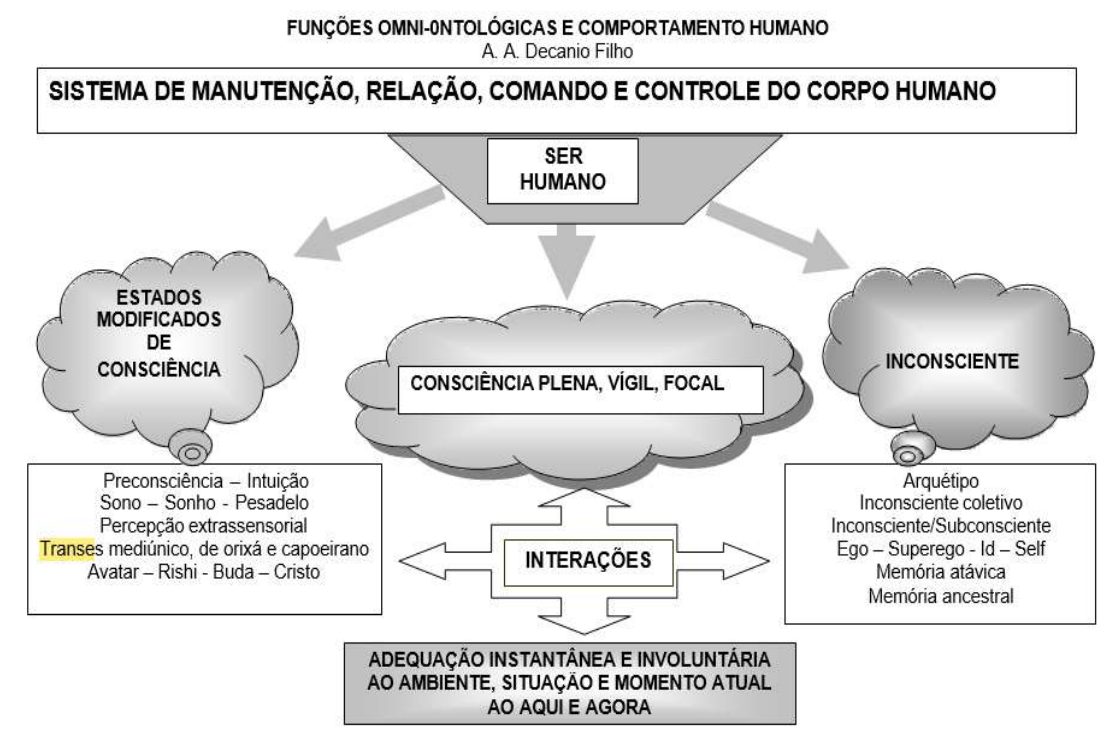

Fonte: Filho, 2002, p. 21

Como se pode observar, Decanio propõe um modelo interativo em que "preconsciência", "consciência plena" e "inconsciente" definem, de modo relacional, o estado modificado emocional adequado a cada contexto ou situação. Explica ele: 
De qualquer modo é necessário acentuar que comportamento do "Ser" humano em face duma situação em dado momento, " $a$ qui-e-agora", é determinando pela interação entre a totalidade dos componentes do "Ser" dependendo, portanto, muito da experiência pregressa ou vivência até aquele dado momento histórico (FILHO, 2002, p.20).

Por essa razão é possível falar no transe capoeirano como uma vigilia pessoal instantânea que se dá em cada indivíduo, de modo particular no agora/já e que se desdobra como interação interpessoal, ou como nomeia Roger Bastide, no caso do Candomblé, intermental (BASTIDE, 1978, p. 204). ${ }^{8}$ Isso fica claro em uma passagem de $A$ herança de mestre Bimba na qual se lê:

... o nivel de consciência pode oscilar...

.... da lucidez da consciência plena da vigilia...

... ao transe profundo de integração cósmica...

... como descrito na linguagem védica...

... da meditação transcendental por Maharishi!(FILHO, 1997, p.50)

\section{Considerações finais}

Que conclusões, portanto, se pode chegar a partir dos elementos aqui elencados sobre as relações possiveis entre "estados místicos de consciência" e "estados modificados de consciência" a partir das reflexões de William James e mestre Decanio? Como é possivel afirmar o aspecto místico, proposto por Decanio, da capoeira à luz da filosofia de James? Para uma resposta mais objetiva, recupero as quatro características que definem, segundo James, os estados místicos: inefabilidade, qualidade noética, transitoriedade e passividade. No que se refere ao caráter inefável, embora não haja nenhuma reflexão, explícita, aplicada por Decanio ao transe, duas passagens podem ser destacadas como pistas para o aspecto não verbal que caracteriza o cerne da experiência de aprendizagem e prática da capoeira. O primeiro, figura em $A$ herança de mestre Bimba:

...interrogação muda e silenciosa...

...que se refletia inexplicavelmente em minha cabeça...

....ao lado da observação...(FILHO, 1998, p. 96) 
A segunda, presente em Transe capoeirano diz: "A palavra escrita ou falada deve acompanhar e esclarecer os fatos e não ser apenas pronunciadas ou encadeadas logicamente" (FILHO, 2002, p. 29). Obviamente que não estamos diante da expressão de um limite entre o dizer e a experiência, que caracteriza a tradição apofática ou negativa, mas penso ser possivel sustentar, graças ao aspecto de interioridade e particularidade que o jogo exige, não se reduzindo aos manuais ou técnicas objetivas, "cada alunu teinh seu jeitchu...particular...pessoal...intransmissivel", como dizia o mestre Bimba (FILHO, 1998, p.90), uma sabedoria, uma vivência que comporta, sim, um aspecto de inefabilidade.

No que diz respeito à qualidade noética, sustentada em narrativas realizadas por aqueles que experimentaram o transe místico, não resta dúvida de que esta característica é pressuposta no transe capoeirano e, também, na própria tarefa do mestre Dacanio como arauto de uma verdade que é, em última instância, a própria capoeira:

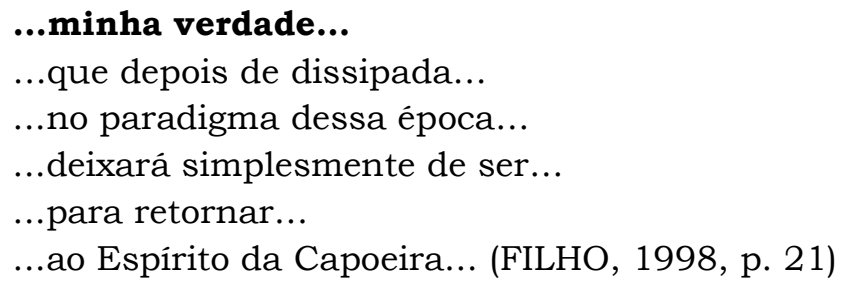

De fato, o verdadeiro conhecimento assume, para Decanio, a imagem do olhar. Um ver que não é simplesmente um ato objetivo fisiológico, mas o desenvolvimento de uma perspectiva determinada que faz da visão um modo próprio de agir e estar no mundo: "A capoeira é o aprendizado do modo de ser" (FILHO, 2002, p. 24).

No que se refere à transitoriedade da experiência, não resta dúvida de que o transe capoeirano, embora com desdobramentos na vida cotidiana, se dá exclusivamente nos instantes marcados pelo som e ritmo do berimbau. Trata-se do instante atemporal do jogo, já abordado anteriormente, e que está presente, de modo mais expressivo, no texto da A herança de mestre Bimba.

Por último, à passividade da experiência mística ${ }^{9}$, associo o aspecto de distensão contínua exigida durante o jogo. Decanio chega mesmo a utilizar o termo "inconsciente" para definir o estado de alerta que não é tensão, mas como já dito, pode ser compreendido como atenção característica, também, da visão periférica. 
Diria que, durante o transe capoeirano, no qual já não há opositores, mas jogadores, é a própria capoeiragem que se manifesta e define as ações dos que se deixam guiar pelos toques do monocórdio de Exú.

\section{Referências bibliográficas}

BASTIDE, R. O candomblé da Bahia (Rito Nagô). $3^{\circ}$ ed. Trad. de Maria Isaura P. de Queiroz. São Paulo: Ed. Nacional, 1978.

BEZERRA, C.C.; TAVARES, L.C.V. Capoeira: devir homem, devir animal.Prometheus - Journal of Philosophy, n. 9(20), 2016.

BEZERRA, C. C.; TAVARES, L.C. V.No limite da roda: capoeira e pensamento. TAVARES, L.C.V. (org.).Capoeira: recortes e percepções. Curitiba: CRV, 2016.

CAMPOS, H. Capoeira Regional: a escola de Mestre Bimba.Salvador: Edufba, 2009.

FILHO, A.A. D.Transe capoeirano, um estudo sobre a estrutura do ser humano $e$ modificações de estados de consciência durante a prática da capoeira. Salvador: CEPAC - Coleção São Salomão, 2002. Disponivel emhttp://www.capoeira.art.br/site/site/administrator/arquivos/download/\%5B monografia\%5D_-_transe_capoeirano.pdf

FILHO, A.A.D. A herança de Mestre Bimba, Filosofia e Lógicas africanas da capoeira. Salvador: CEPAC - Coleção São Salomão 1, 1997. Disponível em https://www.cppa.com.br/attachments / File/Artigos/a_20heran_C3_87a_20de_2 Om_20bimba_202ed.pdf

FILHO, A.A.D. A herança de Mestre Pastinha. Salvador: CEPAC - Coleção São Salomão 3, 1997a. Disponivel emhttp://www.capoeira.art.br/site/site/administrator/arquivos/download/\%5B monografia\%5D_-_a_heranca_de_pastinha.pdf

GALM, E.A. The berimbau: soul of Brazilian music. Mississippi: University Press of Mississippi, 2010.

HALLIWELL, M.; RASMUSSEN, J.D.S. William James and the Transatlantic Conversation. Pragmatism, Pluralism, and Philosophy of Religion. Oxford: Oxford University Press, 2014.

HERÁCLITO.Fragmentos. Trad. de Emmanuel Carneiro Leão. Rio de Janeiro: Tem-po Brasileiro, 1980.

HERRIGEL, E. A arte cavalheiresca do arqueiro zen. Trad. de J.C. Ismael. São Paulo: Pensamento, 1975.

JAMES, W. Varieties of Religious Experience. A Study in Human Nature. London and New York:Routledge, 2002.

NISHIDA, K. Indagación del bien. Trad. de Alberto Luis Bixio. Barcelona: Gedisa, 1995. 
SERRES, M. Variações sobre o corpo. Trad. de Edgard de Assis Carvalho e Mariza P. Bosco. São Paulo: Bertrand Brasil, 2004.

SUZUKI, D.T. Introdução ao Zen-budismo. Trad. de Murilo N. de Azevedo. Rio de Janeiro: Civilização Brasileira, 1971.

VASCONCELOS, N. Naná Vasconcelos, The Voice of the Berimbau.Greg Beyer,
percussive notes, $48, \quad$ october 2007. Disponivel emhttps://www.pas.org/publications/percussive-notes.

TAYLOR, E. William James on Consciousness beyond the Margin.New Jersey: Princeton University Press, 1996.

${ }^{1}$ Roger Bastide, ao se referir aos Orixá, aponta para uma "anatomia mística" que responde à lei das
correspondências, ou seja, o microcosmo reflete o macrocosmo (BASTIDE, 1978, p.157) e aponta
para o fato "real" do transe, bem como para o seu estado de inconsciência demonstrado pelo com-
pleto esquecimento ao despertar (Bastide, 1978, p.205).

${ }^{2}$ Acredito que Decanio concordaria com a perspectiva de James para o qual o cérebro, ao contrário da visão da biologia moderna, não seria um mero produtor da mente, mas um transmissor de consciência como bem ressalta Eugene Taylor (1996, p.83).

3Sobre o tema ver: BEZERRA, C.C. e TAVARES, L.C.V., 2019. p.75-87.

4 Expressão originalmente utilizada por mestre Pastinha e que figura como subtitulo dos seus escritos Quando as pernas fazem mizerês. Material digitalizado em 2003 por Teimosia (Hilton Bruno de Almeida Sousa), parte I, Caderno albo, disponivel em https://www.capoeirashop.fr/img/cms/Manuscritos-Mestre-Pastinha-full.pdf

5 Embora o tema exija um maior desenvolvimento, dada especificidade do emprego da noção de "experiência pura" utilizada por Kitaro Nishida, não é desproporcional associá-la ao que sustenta Decanio, principalmente, no que se refere à relação entre experiência não dualista e a atenção, diz Nishida: "a esfera da experiência pura coincide com a esfera da atenção. Mas a esfera da experiência pura não está necessariamente limitada a um só foco de atenção. Sem agregar a mínima dose de pensamento, podemos deslocar nossa atenção dentro do estado em que sujeito e objeto não estão separados" (Nishida, 1995, p.44).

6 Os negritos fazem parte do estilo de escrita de Decanio.

7 Sobre o aspecto espiritual do Berimbau, Eric A. Galm ressalta sua presença em culturas africanas e diaspóricas africanas como expressão de elementos sobrenaturais que mantém o espaço ambíguo que engloba o sagrado e o profano, o mundo e um "outro" para o qual o acesso só é permitido aos pés do berimbau (Galm, 2010, p. 30).

8 Roger Bastide entende o transe como um "jogo" bem regulamentado em que vários transes, complementam uns dos outros intervindo e promovendo estimulos. Por essa razão, ele prefere o termo "intermental" para distinguir um transe coletivo que seria resolvido isolando os individuos (Bastide, 1978, p.204).

9 É preciso ressaltar que Decanio não emprega os termos mística e místico para caracterizar o transe capoeirano. Quando o faz, conforme já destacado anteriormente, é para referir-se à sua raiz mística, ou seja, o candomblé. 
Recebido em 05/05/2021 Aceito para publicação em 09/06/2021 